\title{
Performance and Analysis of Pediatric Index of Mortality 3 Score in a Pediatric ICU in Latifa Hospital, Dubai, UAE
}

\author{
Dinesh Malhotra $^{a}$ Nadine Nour ${ }^{\mathrm{a}}$ Mahmoud El Halik ${ }^{\mathrm{b}}$ Marwan Zidan ${ }^{\mathrm{c}}$ \\ ${ }^{a}$ Department of Anesthesia and ICU, Latifa Women and Children Hospital, Dubai Health Authority, Dubai, UAE; \\ ${ }^{b}$ Department of Pediatrics, Neonatology Intensive Care Unit, Latifa Women and Children Hospital, \\ Dubai Health Authority, Dubai, UAE; ${ }^{c}$ Medical Research Section, Medical Education and Research Department, \\ Dubai Health Authority, Dubai, UAE
}

\section{Keywords}

Mortality · Pediatric Index of Mortality Score $3 \cdot$ ICU

\begin{abstract}
Introduction: The pediatric index of mortality (PIM) 3 is one of several severity scoring systems used for predicting the outcome of patients admitted to pediatric intensive care units (PICUs) based on data collected within the first hour of admission. It avoids potential bias from the effects of treatment after admission and offers practical utility in assigning children to clinical trials soon after PICU admission. PIM 3 is an updated version of PIM 2 for predicting mortality in the PICU. It provides an international standard based on a large contemporary dataset for the comparison of risk-adjusted mortality among children admitted to intensive care. Objective: The aim was to evaluate the performance of the PIM 3 score in predicting mortality in a tertiary care PICU. Materials and Methods: This was a cohort observational study conducted at a tertiary care PICU from January 2016 to October 2018. All patients between 1 month and 15 years of age who were admitted in the PICU in Latifa Hospital were in-
\end{abstract}

\begin{tabular}{ll}
\hline KARGER & ( 2019 The Author(s) \\
& Published by S. Karger AG, Basel \\
E-Mail karger@karger.com & This article is licensed under the Creative Commons Attribution- \\
www.karger.com/dmj & NonCommercial-NoDerivatives 4.0 International License (CC BY- \\
NC-ND) (http://www.karger.com/Services/OpenAccessLicense). \\
Usage and distribution for commercial purposes as well as any dis- \\
tribution of modified material requires written permission.
\end{tabular}

cluded. PIM 3 scoring was done for all the patients. All data were extracted from the computerized ICU registry database. Scores were calculated using the PIM 3 calculator application. Data were entered into Microsoft Excel 2013 and analyzed using SPSS v24.0. We analyzed the association between PIM 3 score and mortality. The performance of PIM 3 score was assessed by calibration and discrimination. Calibration evaluated PIM 3 at different risks of mortality and was assessed by standardized mortality ratio (SMR) and Pearson's $X^{2}$ goodness-of-fit test. SMR was calculated to a mean probability of death and the ratio of observed-to-expected death rates. Discrimination evaluated how well PIM distinguished between patients who survived and died and was assessed using the area under the curve (AUC) with a 95\% confidence interval $(\mathrm{Cl})$ from the receiver-operating characteristics plot. Results: A total of 583 patients were included in the study, 46 of whom (7.9\%) died. The overall SMR was 0.53 . SMR was 0.33 and 0.72 in the $p<14.3 \%$ and $p>14.3 \%$ group, respectively. The expected mortality rate based on PIM 3 score was 9.2 and $37.5 \%$ in the $p<14.3 \%$ and $p>14.3 \%$ group, respectively. Conclusion: The PIM 3 was used to predict mortality in PICU patients in Latifa Hospital, Dubai. The
Dr. Dinesh Malhotra

Department of Anesthesia and ICU, Latifa Women and Children Hospital Dubai Health Authority, Oud Metha Road, PO Box 4545 Dubai 9115 (UAE)

E-Maildmalhotra@dha.gov.ae 
overall accumulated expected mortality was $87.081(5 \%)$ compared to the observed mortality of $46(7.9 \%)$ and SMR of 0.53 . PIM 3 had acceptable discrimination ability with an AUC of 0.78 (95\% Cl 0.69-0.87). @ 2019 The Author(s)

Published by S. Karger AG, Basel
The objective of this study was to evaluate the usefulness of the PIM 3 for predicting mortality and to validate PIM 3 in children admitted to a single PICU in the tertiary care Latifa Women and Children's Hospital. Additionally, we aimed to determine other factors strongly correlated with the predicted mortality rate.

\section{Materials and Methods}

\section{Study Design}

This was a retrospective cohort study of children admitted to the PICU at Latifa Women and Children's Hospital, Dubai, between January 2016 and October 2018. The probability of mortality for each admitted child was calculated within the first hour of admission and the mortality result was recorded at PICU discharge.

\section{Patient Selection}

All patients between 1 month old and 15 years of age admitted to the PICU at Latifa Women and Children's Hospital, Dubai, during the study period were included in the study. Of 590 patients, 7 were excluded from the study because of incomplete data, so that the final sample consisted of 583 patients.

\section{Data Collection}

The children included in the study were younger than 15 years old at the time of admission. During the study period, there were 583 admissions to the PICU in the Latifa Hospital that met the inclusion criteria. Readmissions were treated as new admissions, and the probability of death was estimated based on the characteristics at the time of the new admission. Data were collected from the computerized ICU registry database. The admission route was via the general ward, emergency room, or operating room.

Demographic data were collected from all study participants, including age, sex, diagnosis. PIM 3 variables such as systolic blood pressure and pupillary reaction to bright light were measured. Other variables assessed were partial oxygen tension $\left(\mathrm{PaO}_{2}\right)$ and $\mathrm{FiO}_{2}$ (at the same time if oxygen was given by endotracheal tube); noninvasive ventilation; base excess in arterial blood gas analysis; the type of mechanical ventilation at any time during the first hour of PICU admission; elective admission to PICU; , recovery from surgery or the procedure that was the main reason for ICU admission; and a low-risk, high-risk, or very high-risk diagnosis. Definitions of these variables and the scoring method were according to the PIM 3 developers' guidelines [5].

Scores were calculated using the PIM 3 calculator application. The variables used to evaluate the PIM 3 score, using a multiple logistic model, are listed in Table 8. Data were entered into Microsoft Excel 2013 and analyzed using SPSS v24.0. We analyzed the association between PIM 3 score and mortality. The performance of PIM3 score was assessed by calibration and discrimination. Calibration evaluated PIM 3 at different risks of mortality and was assessed with the $\chi^{2}$ goodness-of-fit test and the standardized mortality ratio (SMR, calculated as the ratio of observed-to-expected death rates). Discrimination evaluated how well PIM 3 distinguished between patients who survived and died and was assessed using the area under the curve from a receiver-operating characteristics (ROC) plot. 
Table 1. Demographic features and clinical course related to outcome

\begin{tabular}{|c|c|c|c|}
\hline & $\begin{array}{l}\text { Survivors, } \\
n(\%)\end{array}$ & $\begin{array}{l}\text { Nonsurvivors, } \\
n(\%)\end{array}$ & $\begin{array}{l}\text { All patients, } \\
n(\%)\end{array}$ \\
\hline \multicolumn{4}{|l|}{ Gender } \\
\hline Male & $334(93.3)$ & $24(6.7)$ & $358(61.6)$ \\
\hline Female & $201(90.1)$ & $22(9.9)$ & $223(38.4)$ \\
\hline \multicolumn{4}{|l|}{ Age } \\
\hline$<12$ months & $169(90.4)$ & $18(9.4)$ & $187(32.1)$ \\
\hline 12-59 months & $225(93.8)$ & $15(6.3)$ & $240(41.2)$ \\
\hline $60-119$ months & $103(92.8)$ & $8(7.2)$ & $111(19.1)$ \\
\hline$\geq 120$ months & $39(88.6)$ & $5(11.4)$ & $44(7.6)$ \\
\hline \multicolumn{4}{|l|}{ Diagnostics } \\
\hline Respiratory & $159(91.9)$ & $14(8.1)$ & $173(29.9)$ \\
\hline Metabolic & $57(93.4)$ & $4(6.6)$ & $61(10.5)$ \\
\hline Postoperative & $123(100)$ & $0(0)$ & $123(21.2)$ \\
\hline Neurological & $102(91.9)$ & $9(8.1)$ & $111(19.2)$ \\
\hline Cardiovascular & $25(75.8)$ & $8(24.2)$ & $33(5.7)$ \\
\hline Sepsis & $11(52.4)$ & $10(47.6)$ & $21(3.6)$ \\
\hline Others & $56(98.2)$ & $1(1.8)$ & $57(9.8)$ \\
\hline
\end{tabular}

\section{Results}

Over the study period, 583 patients were included, 46 of whom $(7.9 \%)$ died. The mean age of the patients was 37 months (median 12.5 [range 1-180] months). The majority of the patients were male (61.4\%). The most common underlying cause for PICU admission was respiratory $(29.9 \%)$, followed by postoperative $(21.1 \%)$, neurological (19\%), metabolic (10.5\%), cardiovascular (5.7\%), sepsis (3.6\%), and others (9.8\%). The demographic features and clinical course of the patients related to the outcome are provided in Table 1.

The number of patients in the years 2016, 2017, and 2018 were 219 (37.6), 220 (37.8\%), and 143 (24.6\%), respectively. The range of the probability score was $0.2-$ $95.3 \%$ in survivors and $0.2-99.2 \%$ in nonsurvivors, with a mean and median score of 12.8 and $14.3 \%$ among survivors, respectively, and 39.8 and $30.7 \%$ among nonsurvivors, respectively (Table 2). Most subjects were in the 5-15\% score interval. A higher PIM 3 score indicated a higher probability of mortality. Table 3 shows the PIM 3 score intervals and subjects' outcomes.

Table 4 shows the SMR calibration of the PIM 3 model based on the PIM 3 score intervals of $<5 \%, 5-14.99 \%$, and $\geq 15 \%$. SMR was 0.33 in the $p<14.3 \%$ group and 0.72 in the $p>14.3 \%$, respectively. The expected mortality rate based on PIM 3 scores was $9.2 \%$ in the $p<14.3 \%$ group and $37.5 \%$ in the $p>14.3 \%$ group, respectively. The overall accumulated expected mortality was $15 \%$ as compared to the observed mortality of $7.9 \%$ and SMR of 0.53 . AUC analysis
Table 2. Probability score related to outcomes

\begin{tabular}{lrlll}
\hline Outcome & $n$ & $\begin{array}{l}\text { Mean } \\
\text { probability, } \\
\%\end{array}$ & $\begin{array}{l}\text { Median } \\
\text { probability, } \\
\text { score \% }\end{array}$ & $\begin{array}{l}\text { Range of } \\
\text { probability, } \\
\text { score \% }\end{array}$ \\
\hline Survivors & 537 & 12.8 & 14.3 & $0.2-95.3$ \\
Nonsurvivors & 46 & 39.8 & 30.7 & $0.2-99.2$ \\
\hline
\end{tabular}

Table 3. Distribution of probability related to the outcome

\begin{tabular}{|c|c|c|c|}
\hline & $\begin{array}{l}\text { Survivors, } \\
n(\%)\end{array}$ & $\begin{array}{l}\text { Nonsurvivors, } \\
n(\%)\end{array}$ & $\begin{array}{l}\text { All patients, } \\
n(\%)\end{array}$ \\
\hline \multicolumn{4}{|l|}{ Probability } \\
\hline$<5 \%$ & $159(95.8)$ & $7(4.2)$ & $166(28.5)$ \\
\hline $5-14.99 \%$ & $292(97.7)$ & $7(2.3)$ & $299(51.3)$ \\
\hline$\geq 15 \%$ & $86(72.9)$ & $32(27.1)$ & $118(20.2)$ \\
\hline \multicolumn{4}{|c|}{ Median probability } \\
\hline$<14.3$ & $451(97)$ & $14(3)$ & $465(79.8)$ \\
\hline$\geq 14.3$ & $86(72.9)$ & $32(27.1)$ & $118(20.2)$ \\
\hline
\end{tabular}

showed a good discriminatory ability of the PIM 3 score in the interval group to distinguish between survivors and nonsurvivors (AUC >70\%). The AUC of the PIM 3 score was 0.44 in the $p<14.3 \%$ group and overall AUC was 0.78 (95\% confidence interval [CI] 0.69-0.87) (Table 5).

Table 6 shows that SMRs in the overall demographic and the clinical course group were $<1$, except for predicting mortality in sepsis where it was 2.1. Table 7 and Figure 
Table 4. Observed and expected mortality based on the PIM 3 score

\begin{tabular}{|c|c|c|c|c|c|c|c|}
\hline \multirow[t]{2}{*}{ Probability } & \multirow{2}{*}{$\begin{array}{l}\text { Mean } \\
\text { probability, \% }\end{array}$} & \multirow[t]{2}{*}{$n$} & \multicolumn{2}{|l|}{ Survivors } & \multicolumn{2}{|c|}{ Nonsurvivors } & \multirow[t]{2}{*}{ SMR } \\
\hline & & & $\begin{array}{l}\text { observed, } \\
n\end{array}$ & $\begin{array}{l}\text { predicted, } \\
n(\%)\end{array}$ & $\begin{array}{l}\text { observed, } \\
n\end{array}$ & $\begin{array}{l}\text { predicted, } \\
n(\%)\end{array}$ & \\
\hline$<5 \%$ & 1.58 & 166 & 159 & $163.376(98.4)$ & 7 & $2.624(1.6)$ & 2.67 \\
\hline $5-14.99 \%$ & 13.45 & 299 & 292 & $258.793(86.6)$ & 7 & $40.207(13.4)$ & 0.18 \\
\hline$\geq 15 \%$ & 37.5 & 118 & 86 & $73.75(62.5)$ & 32 & $44.250(37.5)$ & 0.72 \\
\hline
\end{tabular}

$\chi^{2}$ goodness-of-fit test $=44.53$ with $p<0.001$.

Table 5. AUC based on the median of the PIM 3

\begin{tabular}{|c|c|c|c|c|c|c|c|c|}
\hline \multirow{2}{*}{$\begin{array}{l}\text { Median } \\
\text { probability }\end{array}$} & \multirow{2}{*}{$\begin{array}{l}\text { Mean } \\
\text { probability, } \\
\%\end{array}$} & \multirow[t]{2}{*}{$n$} & \multicolumn{2}{|l|}{ Survivors } & \multicolumn{2}{|c|}{ Nonsurvivors } & \multirow[t]{2}{*}{ AUC } & \multirow[t]{2}{*}{ SMR } \\
\hline & & & $\begin{array}{l}\text { observed, } \mathrm{p} \\
n\end{array}$ & $\begin{array}{l}\text { predicted, } \\
n(\%)\end{array}$ & $\begin{array}{l}\text { observed, } \\
n\end{array}$ & $\begin{array}{l}\text { predicted, } \\
n(\%)\end{array}$ & & \\
\hline$<14.3 \%$ & 9.2 & 465 & 451 & $422.168(90.8)$ & 14 & $42.832(9.2)$ & $0.44(0.29-0.59)$ & 0.33 \\
\hline$\geq 14.3 \%$ & 37.5 & 118 & 86 & $73.75(62.5)$ & 32 & $44.25(37.5)$ & $0.726(0.62-0.83)$ & 0.72 \\
\hline All & 14.9 & 583 & 537 & $495.918(85)$ & 46 & $87.082(15)$ & $0.78(0.69-0.87)$ & 0.53 \\
\hline
\end{tabular}

$\chi^{2}$ goodness-of-fit test $=26.8$ with $p<0.001$.

1 show the AUC of the PIM 3 score ROC analysis (AUC $>0.7$ is considered to be acceptable for predicting death and survival). Table 8 shows the PIM 3 variables and formula for the calculation of the probability of death.

\section{Discussion}

The inclusion of patient data from children admitted to general ICUs may help improve the performance of our model among children admitted to nonpediatric ICUs. When monitoring PICU outcomes, it is desirable to monitor performance using both the international standard (PIM 3) as well as a locally calibrated version of the model, where the overall SMR for the local population $=1$. A locally calibrated model will allow ICUs to compare their performance with local standards of care. If performed regularly, e.g., at intervals of 1 or 2 years, local calibration also overcomes the issue of calibration drift due to improvements in quality of care and changes in case-mix. To standardize the nomenclature, we recommend that the region and the final year of data be added to PIM 3; PIM3-ANZ [7] denotes a model calibrated using data from Australia and New Zealand, corresponding to the study period reported here. Assessment against an international standard is also important as there may be factors in the health care system that affect the outcomes of children in the region more generally. These factors will not be appreciated if the only assessment is a local comparison. The use of a larger and more geographically diverse patient population in the future may help to improve the generalizability of the model to other settings.

Our study investigated 583 PICU patients at Latifa Women and Children's Hospital, Dubai, UAE, between January 2016 and October 2018 (3 years), in order to evaluate the performance of PIM 3 , in terms of its calibration and discrimination ability, compared with what has been observed in developed countries. The study showed that the PIM 3 had an acceptable discrimination ability (AUC 0.78 [95\% CI 0.69-0.87]). This finding was similar to an Italian validation study which reported that PIM 3 more accurately predicted mortality risk than PIM 2 [8]. Therefore, the PIM 3 score may be a reasonable choice for pediatric ICUs in Dubai, UAE, despite its additional complexity.

The prevalence of mortality in our PICU in the 3-year period was 15\%, much lower than that of Honna et al. [9] at $45.7 \%$. The prevalence of PICU mortality was also lower than that reported from India in 2011 (46.2\%) [10] and Pakistan in 2006 (28.7\%) [11]. 
Table 6. Performance of PIM 3 related to different groups

\begin{tabular}{|c|c|c|c|c|c|c|c|c|}
\hline & \multirow{2}{*}{$\begin{array}{l}\text { Mean } \\
\text { probability, } \\
\%\end{array}$} & \multirow[t]{2}{*}{$n$} & \multicolumn{2}{|l|}{ Survivors } & \multicolumn{2}{|c|}{ Nonsurvivors } & \multirow[t]{2}{*}{ SMR } & \multirow[t]{2}{*}{$x^{2}$} \\
\hline & & & $\begin{array}{l}\text { observed, } \\
n\end{array}$ & $\begin{array}{l}\text { predicted, } \\
n(\%)\end{array}$ & $\begin{array}{l}\text { observed, } \\
n\end{array}$ & $\begin{array}{l}\text { predicted, } \\
n(\%)\end{array}$ & & \\
\hline Gender & & & & & & & & 50.16 \\
\hline Male & 14.96 & 358 & 334 & $304.442(85)$ & 24 & $53.558(15)$ & 0.45 & \\
\hline Female & 14.82 & 223 & 201 & $189.97(85.2)$ & 22 & $33.04(14.8)$ & 0.66 & \\
\hline Age & & & & & & & & 24.02 \\
\hline$<12$ months & 15.19 & 187 & 169 & $158.595(84.8)$ & 18 & 28.405 (15.2) & 0.63 & \\
\hline 12-59 months & 15.12 & 240 & 225 & $203.696(84.9)$ & 15 & $36.304(15.1)$ & 0.41 & \\
\hline $60-119$ months & 14.27 & 111 & 103 & $95.161(85.7)$ & 8 & $15.839(14.3)$ & 0.51 & \\
\hline$\geq 120$ months & 14.07 & 44 & 39 & 37.808 (85.9) & 5 & $6.192(14.1)$ & 0.81 & \\
\hline Diagnostics & & & & & & & & 49.9 \\
\hline Respiratory & 13.32 & 173 & 159 & $150.076(86.7)$ & 14 & $22.924(13.3)$ & 0.61 & \\
\hline Metabolic & 12.25 & 61 & 57 & $53.524(87.7)$ & 4 & $7.476(12.3)$ & 0.54 & \\
\hline Postoperative & 11.85 & 123 & 123 & $108.429(88.2)$ & 0 & $14.571(11.8)$ & 0 & \\
\hline Neurological & 18 & 111 & 102 & $91.015(82)$ & 9 & $19.985(18)$ & 0.45 & \\
\hline Cardiovascular & 25.2 & 33 & 25 & $24.675(74.8)$ & 8 & $8.325(25.2)$ & 0.96 & \\
\hline Sepsis & 22.95 & 21 & 11 & $16.182(77)$ & 10 & $4.818(23)$ & 2.1 & \\
\hline Others & 13.84 & 57 & 56 & $49.114(86.2)$ & 1 & $7.886(13.8)$ & 0.12 & \\
\hline
\end{tabular}

All $p$ values for the $\chi^{2}$ goodness-of-fit test are $<0.001$.

We observed a high SMR of 2.1 with sepsis, followed by 0.96 with cardiovascular, 0.61 with respiratory, and 0.54 with metabolic causes. However, an SMR $>1$ suggests that the performance of the ICU is poor. The high unadjusted mortality may be explained by the severity of illness of patients in the ICU or by the poor performance of the ICU team.

All SMR values were $<1$, suggesting a good ICU performance, except for the 1-5\% probability group which had an SMR value of 2.67, indicating that the actual mortality was 2.67 times higher than expected, and the sepsis group.

To clarify the actual cause, the SMR, which is the observed mortality rate divided by the cumulated predicted mortality, can be calculated. The SMR is the most commonly used parameter of ICU quality in western Europe and is mandated by some countries [12]. It can also be used to compare mortality data, follow changes over time, and evaluate the effect of interventions or events [13-16]. To calculate the SMR, the predicted mortality must first be determined. In this study, the observed mortality was lower than the predicted mortality. When the illness is severe, severity can affect the physiological parameters recorded at the time of ICU admission, and eventually the SMR.

Variation in the predicted mortality according to the scoring system can also influence the SMR [17]. In Latin America, PIM 2 was reported to be inadequate because of poor calibration [18]. Some countries have tried to de-

Performance and Analysis of PIM 3 Score in PICU
Table 7. Area under the curve (AUC) for the PIM score related to different groups

$\begin{array}{ll}\text { Gender } & \\ \text { Male } & 0.79(0.68-0.91) \\ \text { Female } & 0.76(0.62-0.9) \\ \text { Age } & \\ \quad<12 \text { months } & 0.75(0.6-0.89) \\ 12-59 \text { months } & 0.79(0.65-0.93) \\ \text { 60-119 months } & 0.82(0.6-1) \\ \text { >120 months } & 0.77(0.44-1) \\ \text { Diagnostic } & \\ \text { Respiratory } & 0.77(0.62-0.92) \\ \text { Metabolic } & 0.67(0.27-1) \\ \text { Postoperative } & n . a . \\ \text { Neurological } & 0.74(0.53-0.95) \\ \text { Cardiovascular } & 0.88(0.74-1) \\ \text { Sepsis } & 0.7(0.4-0.94) \\ \text { Others } & 1(1-1)\end{array}$

velop a calibrated mortality prediction model because of regional differences among ICUs $[5,19]$. Despite its defects, the SMR based on predicted mortality rates can provide valuable information. For example, serial measurements of ICU SMRs can be used to monitor internal quality improvements in hospitals. At the national level, the SMR of PICUs can be measured every year to evaluate the improvement of the quality of PICUs in Dubai, UAE. 


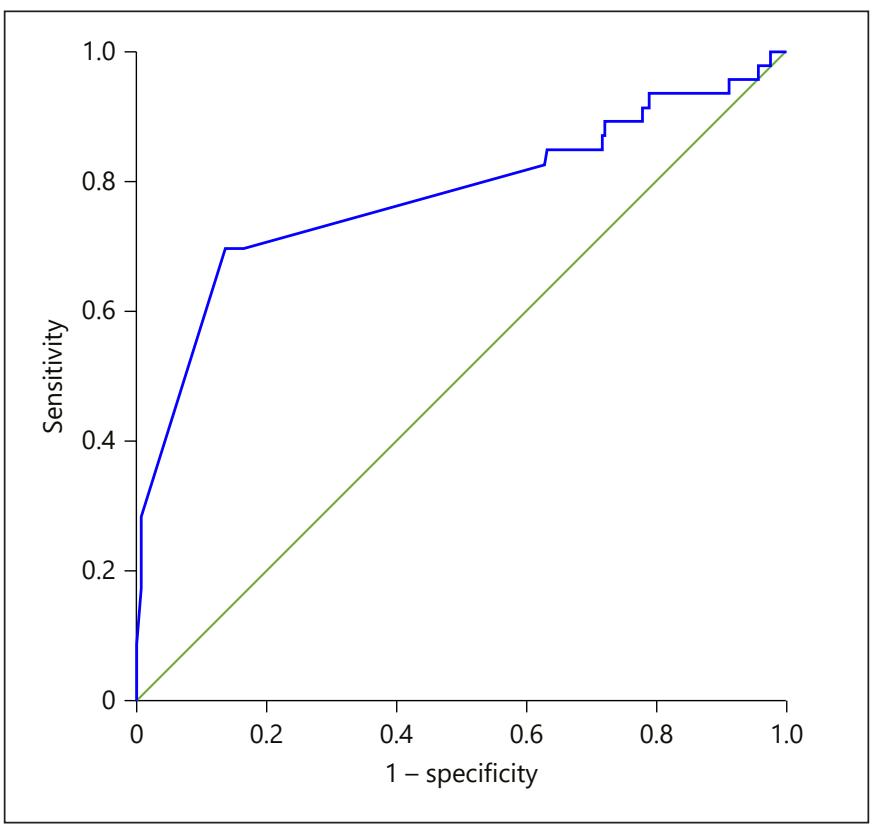

Fig. 1. ROC curve analysis for PIM 3 scores with area under the curve (AUC).

Multiple factors can influence SMR, such as a poor referral system, delayed initial therapy, or complications which can change the outcome, such as hospital-acquired infection, malnutrition caused by hospitalization, or ventilator-associated pneumonia. The overall SMR in this study was 0.53 , which meant that the PIM 3 model overpredicted deaths in our facility. Other studies in developing countries like India [10], Pakistan [11], and Egypt [20] have reported SMRs from PIM 2 scores of 3.3, 1.57, and 1.92, respectively. On the other hand, a Japanese study reported a PIM 2 SMR $<1(0.77)$, which means that the score overpredicted mortality [19].

The discrimination was evaluated by AUC. Discrimination is considered to be very good when the ROC curve is $>0.9$, good when it is $0.80-0.90$, and fair when it is 0.70 0.80 [21]. The AUC was calculated to be 0.781 (95\% CI 0.69-0.87), lower than the AUC in the original places where the PIM 3 studies were undertaken. Many studies using PIM 2 in developing countries have shown good discrimination with AUC values, i.e., 0.81 (95\% CI 0.750.87 ) in Pakistan [11], 0.795 (95\% CI 0.715-0.875) in Iran [22], and 0.841 (95\% CI 0.78-0.90) in Africa [21]. However, AUCs from developed countries were found to be as follows: 0.91 in Australia, 0.90-0.93 in New Zealand, 0.85 in the UK, and 0.84-0.86 in Scotland [23].

All the $p$ values for the $\chi^{2}$ goodness-of-fit test showed that the observed mortality numbers were significantly
Table 8. PIM 3 variables for the probability of death calculation

SBP at admission

Pupils fixed to light, $\mathrm{Yes} / \mathrm{No}$

$\mathrm{FiO}_{2} \times 100 / \mathrm{PaO}_{2}, \mathrm{~mm} \mathrm{Hg}$

Absolute (base excess)

Mechanical ventilation in the first hour, Yes/No

Elective admission, Yes/No

Recovery postoperatively

From bypass cardiac surgery

From nonbypass cardiac surgery

From a noncardiac procedure

Risk factors

Low-risk diagnosis: asthma, bronchiolitis, croup, obstructive sleep apnea, diabetic ketoacidosis, and seizure disorder. High-risk diagnosis: spontaneous cerebral hemorrhage, cardiomyopathy or myocarditis, hypoplastic left heart syndrome, neurodegenerative disorder, and necrotizing enterocolitis. Very high-risk diagnosis: cardiac arrest, severe combined immune deficiency, leukemia or lymphoma after first induction, bone marrow transplant recipient, and liver failure.

Calculation of PIM3 (and PIM3 risk of death \%) - PIM3val = $\left(3.8233^{*}\right.$ pupils $)-\left(0.5378^{*}\right.$ elective $)+(0.9763 *$ MechVent $)+$ $\left(0.0671^{*}\right.$ [absolute base excess $\left.]\right)-\left(0.0431^{*} \mathrm{SBP}\right)+$ $(0.1716 *[\mathrm{SBP} * \mathrm{SBP} / 1,000])+\left(0.4214 *\left[100 * \mathrm{FiO}_{2} / \mathrm{PaO}_{2}\right]\right)-$ (1.2246*Recov_CardBypPr) - (0.8762*Recov_CardNonBypPr) $(1.5164 *$ Recov_NonCardPr $)+\left(1.6225^{*}\right.$ VHRdiag $)+$ (1.0725*HRdiag) - (2.1766*LRdiag) -1.7928

PIM3 risk of death $=\mathrm{ePIM} 3 \mathrm{val} /(1+\mathrm{ePIM} 3 \mathrm{val})$

less than the expected mortality numbers, which indicates that our ICU unit did very well.

Our study has several limitations. First, it was a singlecenter study conducted at a tertiary hospital. The findings may therefore not be generalizable to the entire pediatric population of the UAE. Dubai is a cosmopolitan state comprising about 200 nationalities. Multicenter studies that include primary and secondary hospitals are needed. The second limitation was the retrospective data collection, although every effort was made to validate the data thoroughly. Presently, the process of incorporating the PIM 3 score into our electronic data system is underway to obtain prospective data.

We found that the PIM 3 score had good calibration and was a consistent guide to the performance of our PICU in a pediatric population $<15$ years. Great care has to be taken to ensure that the data needed to calculate PIM are accurate. The model incorporates the quality of retrieval services in its assessment as well as adjusting for the presence of important premorbid conditions. We recommend that the PIM 3 be used routinely as a mortality prediction model for pediatric intensive care. 


\section{Acknowledgement}

We thank the PICU nursing staff, especially Ms. Elizabeth, for their assistance in data collection.

\section{Statement of Ethics}

All data were collected and analyzed retrospectively in this study. The study was approved by the Dubai Scientific Research Ethics Committee (DSREC) of the Dubai Health Authority (DHA) vide reference No. DSREC-12/2018_04.

\section{Disclosure Statement}

The authors have no potential conflicts of interest to disclose.

\section{Funding Sources}

There was no funding.

\section{Author Contributions}

D.M.: Design, data acquisition, manuscript drafting, critical analysis, and final approval.

N.N.: Conception, analysis, manuscript drafting, critical analysis, and final approval.

M.E.H.: Analysis, manuscript drafting, critical analysis, and final approval.

M.Z.: Data analysis, manuscript drafting, critical analysis, and final approval.

\section{References}

1 Garland A. Improving the ICU: part 1. Chest. 2005 Jun;127(6):2151-64.

2 Marcin JP, Pollack MM. Review of the methodologies and applications of scoring systems in neonatal and pediatric intensive care. Pediatr Crit Care Med. 2000 Jul;1(1):20-7.

3 Straney L, Clements A, Parslow RC, Pearson G, Shann F, Alexander J, et al; ANZICS Paediatric Study Group and the Pediatric Intensive Care Audit Network. Paediatric index of mortality 3: an updated model for predicting mortality in pediatric intensive care*. Pediatr Crit Care Med. 2013;14(7):673-81.

4 Pollack MM, Patel KM, Ruttimann UE. PRISM III: an updated pediatric risk of mortality score. Crit Care Med. 1996 May;24(5): 743-52.

5 Slater A, Shann F, Pearson G; Paediatric Index of Mortality (PIM) Study Group. PIM 2: a revised version of the pediatric index of mortality. Intensive Care Med. 2003 Feb;29(2):27885.

6 Jeffries HE, Soto-Campos G, Gall C, et al: Pediatric Index of Cardiac Surgical Intensive Care Mortality Risk Score for Pediatric Cardiac Critical Care. Pediatr Crit Care Med. 2015; 16:846-52.

7 Jung JH, Sol IS, Kim MJ, et al. Validation of Pediatric Index of Mortality 3 for predicting mortality among patients admitted to a pediatric intensive care unit. Acute Crit Care. 2018;33(3):170-7.

8 Wolfler A, Osello R, Gualino J, Calderini E, Vigna G, Santuz P, et al.; Pediatric Intensive Therapy Network (TIPNet) Study Group. The importance of mortality risk assessment: validation of the pediatric index of mortality 3 score. Pediatr Crit Care Med. 2016 Mar; $17(3): 251-6$.
9 Honna L, Triratna S, Triwani T, Theodorus T. Use of pediatric logistic organ dysfunction in determining prognosis among pediatric intensive care unit patients. Paediatr Indones. 2016;50(6):347-50.

10 Gandhi J, Sangareddi S, Varadarajan P, Suresh S. Pediatric index of mortality 2 score as an outcome predictor in pediatric Intensive Care Unit in India. Indian J Crit Care Med. 2013 Sep;17(5):288-91.

11 Qureshi AU, Ali AS, Ahmad TM. Comparison of three prognostic scores (PRISM, PELOD and PIM 2) at pediatric intensive care unit under Pakistani circumstances. J Ayub Med Coll Abbottabad. 2007 Apr-Jun;19(2): 49-53.

12 Flaatten $\mathrm{H}$. The present use of quality indicators in the intensive care unit. Acta Anaesthesiol Scand. 2012 Oct;56(9):1078-83.

13 Kramer AA, Higgins TL, Zimmerman JE. Comparing observed and predicted mortality among ICUs using different prognostic systems: why do performance assessments differ? Crit Care Med. 2015 Feb;43(2):261-9.

14 Afessa B, Gajic O, Morales IJ, Keegan MT, Peters SG, Hubmayr RD. Association between ICU admission during morning rounds and mortality. Chest. 2009 Dec;136(6):1489-95.

15 Kramer AA, Higgins TL, Zimmerman JE. The association between ICU readmission rate and patient outcomes. Crit Care Med. 2013 Jan;41(1):24-33.

16 Slater A, Shann F; ANZICS Paediatric Study Group. The suitability of the Pediatric Index of Mortality (PIM), PIM2, the Pediatric Risk of Mortality (PRISM), and PRISM III for monitoring the quality of pediatric intensive care in Australia and New Zealand. Pediatr Crit Care Med. 2004 Sep;5(5):447-54.
17 Pearson GA, Stickley J, Shann F. Calibration of the paediatric index of mortality in UK paediatric intensive care units. Arch Dis Child. $2001 \mathrm{Feb} ; 84(2): 125-8$.

18 Arias Lopez MP, Fernández AL, Ratto ME, Saligari L, Serrate AS, Ko IJ, et al; ValidarPIM2 Latin American Group. Pediatric Index of Mortality 2 as a predictor of death risk in children admitted to pediatric intensive care units in Latin America: a prospective, multicenter study. J Crit Care. 2015 Dec;30(6): 1324-30.

19 Imamura T, Nakagawa S, Goldman RD, Fujiwara $T$. Validation of pediatric index of mortality 2 (PIM2) in a single pediatric intensive care unit in Japan. Intensive Care Med. 2012; 38:649-54.

20 Youssef MR, Mosleh H, Labib JR. Assessment of the performance of the pediatric index of mortality 2 (PIM2) among Egyptian pediatric patients admitted to the intensive care. Egypt Pediatr Assoc Gazette. 2014;62(3-4):65-71.

21 Solomon LJ, Morrow BM, Argent AC. Pediatric index of mortality scores: an evaluation of function in the pediatric intensive care unit of the Red Cross War Memorial Children's Hospital. South Afr J Crit Care. 2014;30(1):9-13.

22 Salamati P, Talaee S, Eghbalkhah A, Chaman R, Mokhtari Z, Azarshahin M. Validation of pediatric index of mortality-2 scoring system in a single pediatric intensive care unit in iran. Iran J Pediatr. 2012 Dec;22(4):481-6.

23 Alexander J, Tregea S, Slater A. Report of the Australian and New Zealand Pediatric Intensive Care Registry, 2010. Melbourne: Australian and New Zealand Intensive Care Society; 2012. 